\title{
Arbor
}

\section{La configuración del orden internacional y el factor religioso}

\section{Santiago Petschen Verdaguer}

Arbor CLXXI, 676 (Abril), 787-801 pp.

A lo largo de la historia ha habido unas religiones que han estado muy vinculadas con la tensión política internacional. Actualmente también ocurre así. Cuando la religión está presente en un conflicto político el problema se intensifica, se extiende geográficamente y perdura temporalmente. Los intentos del siglo XX de contar con un gobierno mundial (Sociedad de las Naciones, ONU, G 8, OTAN), han sido, tras el 11 de septiembre, sustituidos por el poder de los Estados Unidos que lo ejerce en el marco de una tensión Norte - Sur. El Islam en el Sur y el judaísmo en el Norte son importantes factores de operatividad en la sociedad internacional a cuya crisis se asoman también las demás religiones.

\section{Una mirada a la historia}

A lo largo de la historia, el factor religioso ha tenido una enorme importancia en la configuración política del orden internacional. Y aunque tiempo atrás pareció que dicha influencia iba camino de su desaparición, los datos con que contamos en nuestros días nos hacen ver que su influjo sigue siendo muy considerable.

En el mundo han existido y siguen existiendo una serie de religiones que muy poco tienen que ver con la política a escala mundial. Son las llamadas religiones «mágicas» o religiones «de dioses funcionales». Cuando se expresan conflictivamente entre sí, lo hacen para potenciar las actitudes surgidas de las diferencias étnicas. Como dice Max Weber este tipo de religiones no tiene tensión frente al orden político del mundo ${ }^{1}$. Las re- 
ligiones del mundo primitivo tuvieron estas características. Todavía existen ahora religiones que las conservan a las que podríamos asimilar ciertas nuevas sectas. Desde la perspectiva que nos ocupa, el rasgo más relevante de ellas es su debilidad. Por ello las situamos con los rasgos político sociológicos de su dimensión menor.

Fueron las religiones universalistas las que debido a su pretensión de implantar su dios para todo el mundo originaron una fuerte tensión política con la excepción del budismo, por sus características íntimamente tolerantes. Al ser el cristianismo, como dice Brissaud, una religión misionera ${ }^{2}$, su difusión a escala mundial se hizo teóricamente para implantar una fraternidad y con métodos persuasivos. A pesar de ello, la actitud exclusivista hizo su mella dado que, en su avanzar, tenía que suprimir dioses y eliminar creencias y actitudes.

La realidad de la expansión excluyente se reafirmó con más coherencia en el Islam. Sus principios y prácticas no son tanto los de una religión misionera cuanto los de una religión política. Aquella implantación fascinante del Islam que a los cien años de la muerte de Mahoma (año 632) consiguió una presencia imperial desde más allá de Samarkanda hasta el centro de Francia (batalla de Poitiers: 732), es una prueba bien clara de ello. Después vino lo que se llamó la segunda expansión del Islam : la formación del Imperio Otomano. Todo un ejemplo de cómo un principio religioso afecta decididamente al orden internacional. La herencia de aquellas conquistas configura la geografía islámica de nuestros días.

$\mathrm{Y}$ así como son distintos desde el punto de vista político e internacional los influjos de las religiones de dioses funcionales y de los dioses universalistas, son también diferentes los conflictos entre una religión universalista y otra particular -sea tribal o nacional-, y los conflictos entre dos religiones universalistas ente sí. Cuando el cristianismo se expandía hacia el norte de Europa hallaba pocas resistencias entre aquellas tribus de religiones mágicas que se veían envueltas por una religión más intelectualizada con unas actitudes humanas más sólidas y unas técnicas de persuasión más elaboradas. Algo parecido aconteció en América. Muy distinto fue el intento cristiano de reconquistar el Islam, acción que se estrelló siempre contra una convicción muy firme y una actitud muy batalladora.

La pretensión de una religión universal de disolver las religiones particulares se asemeja a lo que ocurre entre el monoteísmo y el politeísmo. El monoteísmo alberga por su propia naturaleza una intransigencia fundamental desconocida en el politeísmo. Los templos budistas de China tienen incorporados en sus recintos una diversidad de altares dedicados a los dioses del taoísmo dando la impresión de que allí cabe o puede caber casi toda creencia. 
Una de las situaciones en que el paralelismo entre el cielo y la tierra (la religión y la política), despertó más fervor fue en el Imperio Romano. Numerosos autores quisieron configurar el Imperio a la manera del cielo: un ámbito político regido por un Emperador concebido a imagen de Dios. Resulta curioso ver cuánta fuerza han tenido las ideas religiosas en la construcción de las ideas políticas si tenemos en cuenta la cantidad y la calidad de personas eminentes a las que ganó el relacionar la unidad del Imperio romano con la unidad divina : Tertuliano, Orígenes, Eusebio, San Juan Crisóstomo, San Ambrosio, San Jerónimo, Orosio...etc. ${ }^{3}$.

Tanto pudo la idea de la presencia de un Emperador en el marco eclesiástico que cuando el Islam cerró el Mediterráneo por el sur y por el oriente y la influencia de la «impertinente» Constantinopla quedó marginada, la Iglesia católica romana quiso suscitar otro Emperador que cumpliera en ella el mismo papel que los emperadores del Imperio romano habían desempeñado. Situación internacional que Pirenne sintetizó con su famosa tesis de que fue Mahoma quien hizo posible a Carlomagno ${ }^{4}$.

Dentro del marco de la tensión política aparece un serio problema al encontrarnos con dos religiones que ofrecen unas diferencias opuestas en la misma intimidad de sus concepciones. Me refiero a la oposición entre el judaísmo y el cristianismo. Al hallar los judíos que Jesús -a pesar de que era fiel y cumplidor-, tenía unas ideas que se oponían a sus principios y actitudes, tomaron la decisión de eliminarle presionando al poder político de Roma para que le llevase al cadalso. La respuesta de los cristianos no se hizo esperar. Llamaron a los judíos pueblo deicida y consideraron que Dios les había castigado a andar errantes sin territorio propio hasta el fin de los siglos. Su vida, frecuentemente en guetos, en el interior del marco europeo, se vio entorpecida con numerosas persecuciones y castigos. España, Gran Bretaña, Francia, Alemania, Polonia, Rusia, fueron teatro de numerosas acciones que el pueblo judío tuvo que sufrir angustiosamente. Incluso el injusto y terrible holocausto fue originado en el marco de un país cristiano : Alemania. La idea religiosa a la que se unían otros aspectos de carácter étnico, económico, social, ha estado siempre en la base de tal persecución.

No cabe duda que el hostigamiento histórico de los cristianos a los judíos ha sido un aspecto del orden internacional de muchos siglos. Una persecución que tuvo su contrapartida. Una buena parte de los judíos expulsados de la Europea cristiana se marcharon al mundo musulmán: norte de Africa, Turquía, los Balcanes ocupados por el Imperio Otomano, en donde se originaron entre los adeptos de ambas confesiones, unas relaciones tradicionalmente pacíficas. 


\section{Problema político y problema religioso}

El cambio desfavorable que se ha producido en el siglo pasado entre judíos y musulmanes contrasta con el cambio favorable entre judíos y cristianos. Son unos cambios que nos ofrecen una oportunidad muy aleccionadora de tratar, sobre bases concretas, de lo que sucede cuando el problema político se confunde y mezcla con el problema religioso. En el caso al que nos referimos, territorio, ciudad y lugar de culto disputados, potencian por su condición religiosa, el problema político. Los tres símbolos esenciales de identidad -Eretz Israel, Jerusalén y el Templo-, son para todos los judíos aunque de manera especial para los que tienen fe, como nos muestran las numerosas manifestaciones hechas por los ortodoxos, elementos fundamentales de sus objetivos políticos. Es en el Templo de Jerusalén donde, según la liturgia referida al profeta Isaías, se da a conocer la gloria de Yahvé. El Templo, por la promesa que Dios hizo a David, es el lugar definitivamente establecido de la relación con Dios. «El Templo recibe de la Tierra y de Jerusalén -dice Pierre Lenhardt-, no sólo una situación geográfica sino también un status económico, cultural y religioso del que Israel y el mundo no pueden prescindir» ${ }^{5}$. La ciudad de Jerusalén tiene una dimensión religiosa parecida. Ya el profeta Ezequiel la situó en el «centro de las naciones» y la llamó «ombligo de la tierra». Mientras los cristianos y los musulmanes utilizan la expresión «Santos Lugares», la religión de los judíos no está ligada a «lugares» sino a la tierra; no a lo que ocurrió en Jerusalén sino a Jerusalén mismo ${ }^{6}$. De ahí la irrenunciabilidad de los judíos a ceder Jerusalén y su insistencia en repetir constantemente: «Jerusalén, la capital de Israel, es una ciudad única, íntegra e indivisible y permanecerá siempre bajo soberanía de Israel» ${ }^{7}$. Aunque el párrafo está tomado del programa de Netanyahu, es una persuasión en la que coinciden los judíos, especialmente los religiosos. Tampoco hay que olvidar que los que participan de la fe ortodoxa confían en la venida del Mesías, la reconstrucción del Templo y la irradiación de Jerusalén como centro del mundo. En la actualidad, al estar destruido el Templo, la acción de Dios se halla escondida pero se manifestará vigorosamente cuando el edificio se reconstruya y Dios vuelva a estar en él. En tercer lugar está la tierra de Israel (Eretz Israel), la tierra que Dios les asignó y a la que no ven solamente como lugar de engrandecimiento y seguridad (relativa), sino que es profundamente amada arcausa de Dios. Por ello, cuando al movimiento sionista se le planteó la posibilidad de construir el Estado de Israel en otro lugar de la geografía -aunque hubo en algunos, algún momento de vacilación-, el objetivo perseguido de volver a la misma tierra de los antepasados fue considerado un elemento esencial. 
Cuando con los problemas políticos, se mezclan problemas religiosos, la complicación aumenta muy considerablemente. La cuestión empeora y la dificultad se intensifica, se agranda, perdura.

\section{a) La intensificación del problema}

En el caso que nos referimos, al problema territorial se le añade otro de carácter simbólico e identitario. Para los judíos se trata de un territorio (Eretz Israel) y de una ciudad, Jerusalén, entregados por Dios al pueblo israelita que resultan, por consiguiente, irrenunciables. Los judíos ortodoxos viven esta cuestión con una particularmente intensidad frente a los palestinos y frente a la comunidad internacional. Lo expresan muy bien Martin E. Marty y R. Scott Appleby cuando, en el estudio sobre el fundamentalismo, realizado por numerosos autores, concluyen que la composición étnica de una sociedad compleja está formada por diversas entidades básicas «y esas están más agudamente divididas si en ellas se mezcla la religión» ${ }^{8}$.

\section{b) La extensión geográfica del problema}

Lo que podría ser un problema reducido a los judíos de Israel y a los palestinos, viene a convertirse, debido a la dimensión religiosa del mismo, una disputa entre judíos y musulmanes de todo el mundo. La cumbre de Rabat en 1969, que creó la Organización de la Conferencia Islámica, tuvo lugar a raíz del incendio provocado en la mezquita de Al-Aqsa. Y en la Carta de la Conferencia Islámica se establece que se fija como sede provisional de la Organización, la ciudad de Jeddah, hasta que sea posible trasladarla a Jerusalén tras su recuperación. Ello hace que sean no sólo los palestinos sino todos los estados musulmanes los que polaricen su interés en la consecución de la ciudad como algo propio.

\section{c) La perduración temporal del problema}

Si el problema fuera meramente territorial, el llegar a un acuerdo se contemplaría como una posibilidad en el tiempo. En cambio, la dimensión religiosa del mismo hace de él una cuestión intemporal. En consecuencia, lo que dijimos de Jerusalén, capital eterna. Los musulmanes lo consideran también lugar irrenunciable para ellos por motivos del mis- 
mo tipo. La mención del templo (aunque no se nombre a Jerusalén), aparece en varias partes del Corán y particularmente en la sura 17 en donde se habla del viaje nocturno (místico) de Mahoma.

\section{Orden internacional actual y religión}

El siglo XX ha intentado organizar el mundo desde un núcleo de gobierno que tuviera autoridad sobre todo el planeta. Los intentos más claros han sido el de la Sociedad de las Naciones y el de la Organización de las Naciones Unidas. Pero ninguno de los dos ha llegado a conseguir un resultado eficaz sostenible. De ahí que hayan aparecido otros intentos como el del G8 y el de la OTAN. El profesor Paolo Fois ha sabido destacar con mucha agudeza cuáles son los principios que las dos instituciones has sabido encontrar como fundamento legitimador de su pretensión de ámbito mundial. Son respectivamente el principio de globalización y el principio de injerencia humanitaria ${ }^{9}$. Los dos intentos están íntimamente relacionados sobretodo porque los seis miembros de mayor influjo se hallan en ambas organizaciones. A saber: los Estados Unidos, Canadá, Gran Bretaña, Francia, Alemania e Italia. Estos cuatro, además, unidos entre sí en el marco de la Unión Europea. Pero son los Estados Unidos los que llevan la batuta en las dos orquestas. A ambas se ha acercado la Federación Rusa si bien con limitaciones pero con la esperanza de poderse implicar más.

Pero lo sucedido el once de septiembre ha dado a los Estados Unidos una gran oportunidad de ejercer en exclusiva su propio liderazgo. Para lanzarse a una guerra llamada contra el terror ha organizado a los países del hemisferio norte, con mano bastante maestra, a juzgar por los resultados obtenidos. Vinculó íntimamente a Gran Bretaña en la operación militar, comprometió a los restantes países europeos, se avino con la Federación rusa, ajustó a China de una forma impensable poco tiempo antes como se vio en la cumbre de la APEC en Shangai, se hizo ofrecer de parte de Pakistán unos favores esencialísimos, colocó las piezas de los países árabes e islámicos en una posición bastante favorable para los intereses norteamericanos en la guerra. Todo ello lo han hecho los Estados Unidos por medio de pactos secretos. Dados los intereses en juego y el alto nivel de los compromisos, nadie puede dudar de la existencia de tales pactos ${ }^{10}$. Hay quien ha dicho que se ha venido a crear algo así como una nueva ONU, mientras a la ONU existente -en la decisión fundamental-se la ha arrinconado. Cuando ha ido acabando la guerra la ONU ha sido llamada a operar. Así ha interesado a los Estados Unidos que no 
sólo se ha impuesto sobre los Estados sino también sobre las Organizaciones Internacionales. Por lo que respecta a los Estados vale decir que para saber cómo está hoy un estado en la sociedad internacional, lo primero que hay que conocer es cómo es su relación con los Estados Unidos. $\mathrm{Y}$ por lo que se refiere a las Organizaciones Internacionales, después de lo que dijimos acerca de la ONU, cabe añadir que la experiencia de Kosovo aconsejó excluir a la OTAN de Afganistán y que a la Unión Europea se le asignó la reconstrucción del país después del castigo bélico. Incluso la Liga Arabe y la Organización de la Conferencia Islámica fueron situadas en la posición que más convenía al coloso de nuestro tiempo. William Pfaff lo ha dicho muy bien cuando ha escrito que la voluntad política que necesitaban los Estados Unidos para ejercer su enorme poderío, se la proporcionó el once de septiembre.

Ese gobierno del mundo que bien podemos llamar nuevo, porque se conforma con la pretensión de un Estado, ha sido asumido por los Estados Unidos y aceptado por todos los demás. Como tal tiene unas características propias de las que conviene destacar algunas. La más relevante es la del unilateralismo. Aunque en Afganistán haya tenido que considerar los intereses del gran juego del petróleo dando cierta cancha a británicos y a rusos (éstos entraron libremente en Kabul), han sido los Estados Unidos los que han proyectado, dirigido y llevado a cabo la guerra. En segundo lugar, su secretismo y la manipulación de la opinión pública. Secretismo en los pactos a los que antes nos referimos para conseguir la adhesión de todos en la ocupación del lugar que a cada uno se le ha asignado. Una operación tan gigantesca y plural no hubiera sido posible sin la utilización de esos pactos secretos. Manipulación de la opinión pública que, en el ámbito de una guerra totalmente sui generis, más necesita ser engañada. Por último, utilización de sistemas de recompensas (las primeras de todas ellas para Paquistán con la supresión de las limitaciones que anteriormente tenía), de amenazas (como -aunque en otro marco-, con Nicaragua antes de las pasadas elecciones) y presiones (por medio del embargo).Y ello para conseguir dirigir a un conglomerado tan nutrido de Estados y de Organizaciones Internacionales que, en ausencia de tan variados métodos, sería imposible lograr.

Toda una organización del hemisferio norte poderoso, con un estilo y unos medios para controlar al mundo. Un mundo en el que aparece un sur miserable y desesperado pero no por ello menos controlado, en donde se hallan una serie de países como Somalia, Yemen del Sur, Sudán, que todavía están en el punto de mira del castigo.

En ese orden internacional la religión tiene su particular forma de presencia. En el Sur y frente al problema que para él le representa el Norte, 
destaca el Islam. En el Norte, y frente al problema que le representa el Sur tiene una presencia pequeña pero muy influyente el judaísmo. Las otras religiones, más distantes de la confrontación están en situación de hacer su aportación de una manera más imparcial y equilibrada.

\section{A) El Sur y el Islam}

Es evidente que el Sur no se identifica con el Islam. Ni por la geografía, ni por la creencia religiosa, ni por la economía, ni por la política. Sin embargo, en la oposición que existe entre el Norte y el Sur, el Islam ha ocupado el lugar de vanguardia en la manifestación de hostilidad que el abismo diferencial genera. Las mismas características de ciertas tendencias (agresividad, rigorismo), le hacen muy adecuado para representar el papel que la división del mundo parece haber depositado en sus manos.

Si una de las formas más profundas, amplias y eficaces con que la religión opera en el orden internacional es por medio de las civilizaciones, el Islam lo cumple de forma destacada. La civilización islámica afronta la realidad del sur en donde se halla inserta como un importante factor de unidad, de concienciación y de protesta. El mundo islámico tiende a considerarse solidariamente uno y quiere ser, de una u otra forma, unitario. Es el mandato que los musulmanes recibieron de Mahoma. Una unidad que no sólo debe ser espiritual como la exigida en el cristianismo sino también política. Ello no impide que haya grandes divisiones tanto religiosas - sunismo (encabezado exitosamente por Arabia Saudí) y chiismo (dirigido, con escasa capacidad de difusión, por Irán) ${ }^{11}$-, como políticas (los Estados, cada uno con sus particularidades nacionales) y económicas (de los Países del Golfo hasta Bangladesh y Mali). De esa forma, una parte de los musulmanes parece conectar mejor a título particular con el Norte que con el Sur. Ello, no obstaculiza, sin embargo, la operatividad del principio de unidad como nos demuestra la existencia de la Organización de la Conferencia Islámica y la capacidad de formar organizaciones como la de los Hermanos Musulmanes que pasan por encima de las fronteras del mundo islámico y todavía más la de $\mathrm{Al}$ Qaeda que utiliza el recurso de la emigración para infiltrarse en los países de Occidente. Si no fuera por el Islam, la disgregación del Sur en Asia y Africa, sería parecida a la que existe en el Africa subsahariana no musulmana.

Es también el Islam en el Sur afroasiático un importante factor de concienciación. El Islam conciencia las grandes diferencias que separan a sus comunidades de los países que forman el mundo desarrollado. Una 
La configuración del orden internacional y el factor...

conciencia del gran abismo existente entre la riqueza de unos y la pobreza de otros que llega a ser vivida con gran frustración. Concienciación de la gran división que se ha producido en los países islámicos cuyas clases potentadas y dirigentes están muy vinculadas a Occidente y son consideradas traidoras por las amplias clases populares. El Islam es un instrumento que les hace ver a sus seguidores la situación en que se hallan y las posibilidades que tienen para luchar en favor del cambio entendido como liberación e incluso también muchas veces como venganza.

Una tercera característica es la de la protesta, con características justicialistas, y en ocasiones de rebelión. La experiencia enseña que cuanto más miserable y desesperada es la diferencia, más radical se hace la frustración. Se alimenta de esa forma entonces lo que se conoce con el nombre de fundamentalismo. La potenciación revolucionaria que origina el subdesarrollo económico y el sometimiento político y cultural halla una coincidencia de carácter muy radical y profundo en la yihad islámica. Así lo vio Qotb, que en Egipto supo atraerse a los desheredados, y algún tiempo después Jomeini, en Irán. Desde ese punto de vista, Qotb, al igual que Mawdudi en Paquistán, consideraron que los nacionalismos son impíos y que no se puede concebir a los Estados islámicos con perspectiva occidental sino bajo la unidad política generada por el Islam.

El factor religioso influye también en otras facetas como es por ejemplo, la capacidad de liderazgo. Gran parte de dicha capacidad, como nos muestra el caso de Bin Laden, se debe a la religión. Bin Laden, que abandonó la actitud de la clase alta de Arabia Saudí para identificarse con el mundo doliente de los desheredados, ha desarrollado una elevadísima intensidad en su acción. Una de las pruebas más claras es la consecución de que numerosos de sus súbditos se hallen dispuestos a inmolarse como kamicazes y ser exaltados con orgullo después de muertos, por sus propias familias. Ha cambiado de país diversas veces formando una organización extendida por encima de diversas fronteras y con súbditos de muchas naciones : Arabia Saudí, Afganistán, Sudán...etc. Ha buscado la perduración temporal considerando que la victoria sobre los soviéticos en Afganistán no fuese nada más que la primera de una serie de ellas que tendrían que producirse después. Sadam Hussein, por el contrario, al no apoyarse en la religión, nunca ha desplegado ni hubiera podido desplegar una acción tan amplia. En la Guerra del Golfo únicamente se acercó a la religión con la finalidad de conquistar a la opinión pública.

El fundamentalismo ha hecho que en diversos estados islámicos se sacralizase la política y la vida civil. Un ejemplo de dicha sacralización la tenemos en la negativa a adoptar una Constitución porque la Constitución es la sharía como ocurre en Arabia Saudí. En esa línea está la im- 
posición de castigos de la sharía tales como la lapidación y la amputación de miembros. A veces las interpretaciones crean unas situaciones extremosas. Los talibán a los hombres acusados de sodomía les imponían como castigo islámico, aunque desconocido hasta entonces, la pena de perecer bajo un muro que derribaban sobre ellos ${ }^{12}$.

\section{B) El Norte y la presión del judaísmo}

En el Norte aparece también un aspecto religioso digno de ser tenido en cuenta. Se muestra claramente en una de las cumbres del iceberg de la lucha Norte-Sur : el conflicto palestino-israelí. Me refiero al judaísmo como religión que en este caso actúa con la operatividad de los círculos concéntricos. El círculo más interior son los partidos religiosos judíos -Shas, Judaísmo de la Torah (ambos con 22 escaños de los 120 con los que cuenta la Knesset), Partido Nacional Religioso (que representa a los colonos de Cisjordania y Gaza)-, que consiguen salirse con la suya para conservar el Eretz Israel por medio de las implantaciones de asentamientos. Dicho círculo está rodeado por otro más amplio del todo Israel que resulta así escorado desde dentro. De forma parecida actúan los judíos como grupo de presión en Estados Unidos que ejercen en la sociedad internacional una función de apoyo muy importante para Israel. Impiden que la cuestión sea llevada al Consejo de Seguridad de la ONU. También en la Asamblea de las Naciones Unidas la representación norteamericana ha votado en solitario junto a Israel.

Existe, pues, una notable dejación de los Estados Unidos a la hora de que se consiga la paz en el cercano oriente. En lugar de optar por apoyar lo que establece el derecho internacional con respecto a los territorios ocupados se inclina por hallar una solución dialogada en la que las presiones pueden conseguir mejores resultados sobre la parte más débil que se vio obligada a aceptar la situación de un Estado bantustán. $\mathrm{Si}$, a pesar de haber concretado un pacto, luego ocurre lo que pasó tras los Acuerdos de Oslo, de que los compromisos no se cumplieron, la dejación de la gran potencia resulta todavía más alarmante. De esa forma, el desarrollo de los asentamientos no se ha detenido. El término geográfico de Jerusalén sigue creciendo. Un acto de Sharon en la explanada de las mezquitas provocó la segunda Intifada con todas las manifestaciones de terror que siguieron después impulsadas por una parte por Hamás y la Yihad islámica y por otra por el propio gobierno de Israel.

El once de septiembre parece haber provocado un cambio en los Estados Unidos que no está exento de ambigüedad. A veces ha dado la im- 
presión de que se tomaban la cuestión más en serio pero sin estar motivados por el fondo de la misma sino por una necesidad estratégica (que algunos países musulmanes no se separaran de la coalición contra el terror). El discurso de Bush en la Asamblea General de las Naciones Unidas pareció dar al problema una importancia secundaria. Una conferencia posterior de Colin Powell en una Universidad de Connecticut con la utilización de la palara «ocupación» y la mención del envío de un representante personal a Israel, pareció aumentar la importancia de la atención que se daba al problema aunque sin resultados posteriores concretos.

Entre la relación Norte -Sur y la relación Israel- Palestina aparece un cierto paralelismo. El mismo Bush se encargó de decirlo al comparar a Hamás con Al Qaeda y al actuar contra la Fundación Tierra Santa para el Auxilio y el Desarrollo. La proclamación del derecho a la defensa es similar en uno y otro caso y también las actuaciones (bombardeos, persecuciones). Ni Israel ni los Estados Unidos están dispuestos a acatar los mandatos de la ONU y de un consenso casi universal que -de acuerdo con el derecho internacional con respecto a territorios ocupados-, pide la evacuación de lo conquistado en una guerra, aunque de legítima defensa, en 1967. La guerra contra el terrorismo no ha hecho más que potenciar esta actitud. Cuanto más segura han encontrado los Estados Unidos la victoria en Afganistán, más han seguido favoreciendo a Israel.

$\mathrm{El}$ acercamiento al mundo de occidente, especialmente a los Estados Unidos, ha sido la causa de que se llegue a hablar incluso de civilización judeo cristiana cuando, como explica $\mathrm{Braudel}^{13}$, los judíos tuvieron su propio germen independiente de civilización. Dicho germen no cuajó por no haberse podido desarrollar en una historia de dispersión y con frecuencia de guetos sometidos a la persecución. La civilización judía hubiese sido algo muy distinto a lo que es hoy la civilización occidental. Fueron los judíos los que -abandonando muchos rasgos que les eran propios y que sólo los ortodoxos conservaron-, prefirieron seguir la línea de la Ilustración (ashkalá), que la de la ortodoxia. Una vez dado ese paso de aceptación de las características de una civilización formada ya desde hacía varios siglos, los judíos mostraron la potencialidad de su genio aportando unos valores muy notorios de enriquecimiento filosófico $\mathrm{y}$ científico. No tenemos más que examinar un caso concreto, el de Alemania, tal como Habermas se encarga de expresarlo y valorarlo ${ }^{14}$.

No se trata aquí, con todo, de un problema de civilizaciones tal como Huntington expuso. El Shintoísmo vive alineado con la civilización occidental. A ella se acerca también en nuestros días la civilización eslavo ortodoxa. Lo mismo sucede con amplias capas y sectores del Islam. Y la úl- 
tima aproximación de China a los Estados Unidos parece por el momento alejar la realización de aquella profecía huntingtoniana de la coalición islámico confuciana. Se trata más bien de un distanciamiento enfrentado, Norte-Sur, muy hostil en sus extremos, en el que el factor religioso civilizacional cuenta con una importante presencia.

\section{C) Otras dimensiones religiosas}

Las actitudes de las otras religiones que no se han enfrentado a unas situaciones tan acuciantes con respecto al problema que nos ocupa, son más propensas a la justicia y a la apertura hacia los valores de las demás confesiones. La Iglesia católica ha mostrado una amplitud de miras desconocida hasta los tiempos que corremos. Muy considerable fue el cambio con respecto a los judíos. De la consideración de los judíos como pueblo deicida que inspiraba el rechazo de Benedicto XV y de otros papas al proyectado Estado de Israel, hasta el reconocimiento por parte de Juan Pablo II, en la sinagoga de Maguncia, de que Dios selló una alianza con los judíos que nunca ha sido revocada, media un abismo. En otros documentos de la Iglesia Católica se ha hablado después de la integridad esencial del judaísmo en el proyecto divino de la Humanidad.

También es digna de mención, como novedosamente revolucionaria, la petición del papa a los católicos para que celebraran un día de ayuno el pasado día 14 de diciembre uniéndose a los musulmanes que concluían en dicha fecha la celebración del Ramadán. Ha sido un paso más, por encima de la costumbre de Juan Pablo II de invitar a los dirigentes de diversas confesiones religiosas a reunirse en Asís para orar. En una tónica parecida, hay que situar a numerosos centros de estudio y de foros para promover el acercamiento de las religiones en un marco internacional como los de San Egidio o el de la Fundación Agnelli para formar operarios que se hagan promotores del diálogo interreligioso. En Washington se creó no hace mucho el Center for Religion and Diplomacy con el objetivo de potenciar la diplomacia con un conocimiento más profundo de la dimensión religiosa en orden a realizar una acción más efectiva en la solución de conflictos. Y otros muchos.

Después del once de septiembre, otras religiones han tomado postura parecida. El Consejo Mundial de las Iglesias, en el mensaje de Navidad enviado por el Secretario General de la Organización, hizo referencia a que la gracia de Dios quiebra la dinámica despiadada de las represalias. Los presbiterianos de los Estados Unidos, en carta dirigida al presidente Bush le recordaron que ellos, como grupo religioso, promueven la solu- 
ción pacífica de los conflictos. El texto destacaba que el $25 \%$ de las armas de alta tecnología usadas en Afganistán, había causado la muerte de civiles inocentes y dañado el medio ambiente ya previamente devastado por la sequía y las tormentas. En la Iglesia menonita se expresó que la violencia militar sólo podía traer más odios, más deseos de venganza más enemistades entre los pueblos y actos terroristas más violentos.

Todavía más radical que todas estas manifestaciones se mostró el Dalai Lama que visitó el Parlamento Europeo el pasado 24 de octubre. El líder budista urgió a los Estados Unidos a detener los bombardeos de Afganistán y a abrir un diálogo con los acusados de ser responsables de los ataques terroristas del pasado once de septiembre. Una exigencia de un arrojo y de un desprendimiento muy propio de un budista, no desprovisto por otra parte, de sentido común, si es que se quiere acudir más a las causas que a los efectos concretos de las mismas.

Si nos preguntamos si esta actitud de las religiones se da también en la vida política internacional tendremos que responder afirmativamente si es que nos fijamos en ciertos sectores. Eso sí, con un estilo y, sobre todo, diferente. La motivación política es, por su propia naturaleza, muy distinta de la expresión religiosa. La actitud de Europa guarda un paralelismo en la adopción de posturas que no pierden de vista el equilibrio entre unas pretensiones y sus opuestas. Por lo que respecta a la punta del iceberg de la confrontación político-religiosa Norte-Sur, la situación de Israel-Palestina, los documentos de la Unión Europea se muestran equilibrados. En la guerra de persecución a la cúpula del terrorismo internacional y a sus protectores en Afganistán, a Europa le ha tocado la mejor parte: gastar poco en el conflicto bélico de la destrucción y mucho en la reconstrucción de lo destruido. Lo contrario que a los Estados Unidos: que se ha asignado un gasto enorme para la guerra y sólo aporta, hasta ahora, una pequeña cantidad para la paz. No cabe duda de que esa diferencia es tenida en cuenta por los terroristas. Al Qaeda no ha apuntado a Europa, a pesar de ser, como dice Javier Valenzuela, una zona geográfica bastante más vulnerable que los Estados Unidos. En la conflagración que enfrenta al mundo, una de cuyas manifestaciones más sintomáticas es el terrorismo, las ideas son lo que pueden tener a la larga, más eficacia. Y ahí es donde las religiones pueden aportar mucho. Cierto que el cristianismo y en concreto el catolicismo han sido objeto de amenazas. En algunos medios se habló -extrapolando lo sucedido en algunos lugares del sur de Asia-, de que una acción contra la Basílica de San Pedro en el Vaticano podría ser la respuesta a los ataques de los Estados Unidos en Afganistán durante el mes del Ramadán. Claro que, dado el alto nivel que se ha constatado en esta ocasión de contaminación 
mediática, la propalación de dicha sospecha podría haber sido la consecuencia de una especulación de difusión interesada. La manipulación de la opinión, a través de los medios de comunicación, en este tiempo de la llamada guerra contra el terror, ha contrastado con lo sucedido otras veces. Hay quien ha notado un cambio de actitud en la información dada por la CNN con respecto a la información que dio durante la Guerra del Golfo.

Otra dimensión a tener en cuenta desde el punto de vista de la religión es cómo las partes enfrentadas sitúan a sus enemigos en su perspectiva religiosa. Los islamistas son los más propensos a utilizar anteojeras religiosas. Afirman que se ha levantado una cruzada en contra del Islam, que se persigue a su religión y utilizan una terminología apocalíptica denominando a Occidente «el gran Satán». No han caído en ese vicio los occidentales que frente al fanatismo de sus oponentes se muestran más fríos acostumbrados como están a las concepciones y a las actitudes secularizadas. Responden con tranquilidad a las acusaciones que reciben que su lucha no está dirigida contra el Islam cuyos valores positivos se esfuerzan en destacar sino contra el terrorismo que no concuerda con las enseñanzas coránicas.

Si en las manifestaciones religiosas aparece la política, también en las de los políticos hay un substratum religioso. En boca de los que se sienten islamistas radicales es claro. Pero en el mundo occidental, se utilizan también expresiones de significado religioso como «cruzada contra el terror»o «justicia infinita». No parecen tener mucho sentido. Lo de cruzada tiene unas evocaciones históricas muy negativas. Y la justicia infinita no existe. De lo contrario, no podría ser representada por medio de una balanza. Al decir «justicia infinta» más bien parece que se utiliza un eufemismo que cubra lo que en realidad puede haber debajo : el deseo de «venganza infinta». Ese es el aspecto negativo de la religión también presente en la configuración del orden internacional de nuestros días.

Todavía queda algo por decir a propósito del orden internacional en cuyo centro lo único que puede tener sentido es que sea ocupado por la persona humana. Una persona que según es entendida por la filosofía de los derechos humanos sea el criterio para la construcción de una globalización beneficiosa para todos que sea capaz de superar las abismales diferencias entre el Norte y el Sur. Las religiones aportan al conocimiento de la persona la visión que de ella tienen desde la perspectiva de la muerte.

Después del once de septiembre hemos tenido ocasión de conocer -como es obvio-, diversas manifestaciones de referencia «post mortem». Y muchas de ellas han sido realizadas desde una concepción desigual de la persona. Como si la vida de la gente inocente muerta en Afganistán no 
valiera lo mismo que las de los inocentes muertos en las Torres gemelas. Los Estados Unidos han demostrado poseer una técnica y una capacidad organizativa muy por encima de lo común llevando en Afganistán una campaña bélica de varios meses de duración que sólo ha ocasionado en el personal de sus tropas un número de bajas que en poco sobrepasa la decena. Como consecución técnica es enormemente loable. Se trata de un éxito extraordinario. Pero ello no quiere decir que la vida de los que no perecieron por obra de un alarde técnico tan colosal valga más que la de aquellos que murieron tan sin culpa como tan sin remedio. Después de muertos, aunque sea en general, deben ser también recordados. Ello indicaría que se desea profundamente para todos los seres humanos las mismas oportunidades en la educación, la salud, el trabajo, etc. He aquí un aspecto en el que la religión, desde su perspectiva posterior a la muerte, puede aportar -probablemente en exclusiva-, un elemento muy valioso para una configuración más justa del orden internacional.

\section{Notas}

1 Weber, Max. «Estados y direcciones del rechazo religioso del mundo". Ensayos sobre sociología de la religión I. Taurus. Madrid, 1998, p. 536.

2 Brissaud, Alain. Islam et Chrétienté. Robert Laffont. París, 1991, pp. 36-58.

3 Peterson, Erik. El Monoteísmo como problema político. Ed. Trotta. Madrid, 1999, pp. 65-93.

4 Pirenne, Henry. Mahoma y Carlomagno. Alianza Ed. Madrid, 1978.

5 LenhardT, Pierre. «La Tierra de Israel, Jerusalén y el Templo. Su valor para los judíos y para los cristianos». El Olivo. Documentación y estudios para el diálogo entre judios y cristianos. XX 43-44. p. 50.

${ }^{6}$ Stendahl, Kristel. Citado por VeghaziK, Esteban. "El Significado de Jerusalén para los judíos". El Olivo. Documentación y estudios para el diálogo entre judios y cristianos. XX 43-44. p. 212.

7 Programa político del Gobierno de Netanyahu. 17 de abril de 1996. Párrafo II, 1. Meridiano CERI. No 10. Agosto, 1996. p. 26.

8 MARTy, Martin E. and APPLEBY, R. Scott. Fundamentalismus Comprehended. The University of Chicago Press. Chicago and London, 1995. p. 502. 73-74.

9 FoIS, Paolo. «Il governo mondiale dopo il G8 di Genova». Gli argomenti umani. pp.

10 Fois, Paolo. «La Guerra insidia la libertà di stampa nei paesi occidentali». La Nuova Sardegna. 20 octobre 2001.

11 KePel, Gilles. La Yihad. Península. Barcelona, 2001. pp. 100-112 y 173-204.

12 RaSHID, Amed. Los Talibán. Península. Barcelona, 2001. p. 178.

13 Braudel, Fernand. El Mediterráneo y el mundo mediterráneo en la época de Felipe II. Vol. II. F. C. E. Madrid, 1993. pp. 203-228.

14 Habermas, Jürgen. Israel o Atenas. Trotta. Madrid, 2001. pp. 51-77. 